\title{
Influence of Concentration and Electrodeposition Time on the Electrochemical Supercapacitor Performance of Poly(3,4-Ethylenedioxythiophene)/Graphene Oxide Hybrid Material
}

\author{
Nur Hawa Nabilah Azman, ${ }^{1}$ Hong Ngee Lim, ${ }^{1,2}$ and Yusran Sulaiman ${ }^{1,2}$ \\ ${ }^{1}$ Department of Chemistry, Faculty of Science, Universiti Putra Malaysia (UPM), 43400 Serdang, Selangor, Malaysia \\ ${ }^{2}$ Functional Device Laboratory, Institute of Advanced Technology, Universiti Putra Malaysia (UPM), 43400 Serdang, \\ Selangor, Malaysia \\ Correspondence should be addressed to Yusran Sulaiman; yusran@upm.edu.my
}

Received 14 August 2016; Revised 27 October 2016; Accepted 8 November 2016

Academic Editor: Stefano Bellucci

Copyright (C) 2016 Nur Hawa Nabilah Azman et al. This is an open access article distributed under the Creative Commons Attribution License, which permits unrestricted use, distribution, and reproduction in any medium, provided the original work is properly cited.

\begin{abstract}
Poly(3,4-ethylenedioxythiophene)/graphene oxide (PEDOT/GO) composites with wrinkled paper-like sheets morphology were electropolymerized potentiostatically at $1.2 \mathrm{~V}$ with different electrodeposition times (1-30 min) and various concentrations of GO $(0.5,1.0,1.5$, and $2.0 \mathrm{mg} / \mathrm{mL})$. The electrochemical properties of PEDOT/GO composites as an electrode material for supercapacitor were investigated using cyclic voltammetry, electrochemical impedance spectroscopy (EIS), and galvanostatic charge-discharge (GCD). The CV results revealed that PEDOT/GO containing $1.0 \mathrm{mg} / \mathrm{mL} \mathrm{GO}$ and electropolymerized for 10 minutes exhibited the highest specific capacitance ( $157.17 \mathrm{~F} / \mathrm{g}$ ). This optimum PEDOT/GO was found to have energy and power density of $18.24 \mathrm{~W} / \mathrm{kg}$ and $496.64 \mathrm{Wh} / \mathrm{kg}$, respectively, at $1.0 \mathrm{~A} / \mathrm{g}$ current density. The resistance of charge transfer obtained for PEDOT/GO is very low $(13.10 \Omega)$ compared to PEDOT $(638.98 \Omega)$, proving that PEDOT/GO has a good supercapacitive performance due to the synergistic effect of the high conductivity of PEDOT and large surface area of GO.
\end{abstract}

\section{Introduction}

In recent years, there has been a greater demand for energy storage devices due to the deficiency of energy source. Therefore, the development of energy storage device such as supercapacitor is expanding rapidly. Supercapacitor also known as ultracapacitor is an electrical energy storing device which bridges the gap between batteries and capacitors $[1,2]$. Supercapacitor possesses fast charge-discharge cycle, high power density, and longer life span and is also environmentally friendly compared to battery [3]. Supercapacitor has a potential to deliver greater acceleration (through rapid discharge capability) and enhance the regenerative braking systems (through fast charge capability) for hybrid and pure electric vehicles [4]. However, the energy density of batteries is greater in comparison to supercapacitors [5].
Supercapacitors can be classified into two main categories based on its charge storage mechanism, that is, electric double-layer capacitor (EDLC) and pseudocapacitor. EDLC stores charge non-Faradaically or electrostatically in double layers where there is no electron transfer occurring at the interface of the electrode [6, 7]. Graphene, activated carbon, and carbon nanotubes (CNT) with high porosity and surface area are types of carbon-based materials used for EDLC [8]. Pseudocapacitor which is made up of pseudocapacitive materials, that is, metal oxides and conducting polymers (CPs), stores charges Faradaically or through redox reactions which occur at the electrolyte/electrode interface that contribute the capacitance $[9,10]$.

EDLC compared to pseudocapacitor is able to deliver higher power density and longer life cycle due to the high porosity, mechanical strength, and surface area provided by 


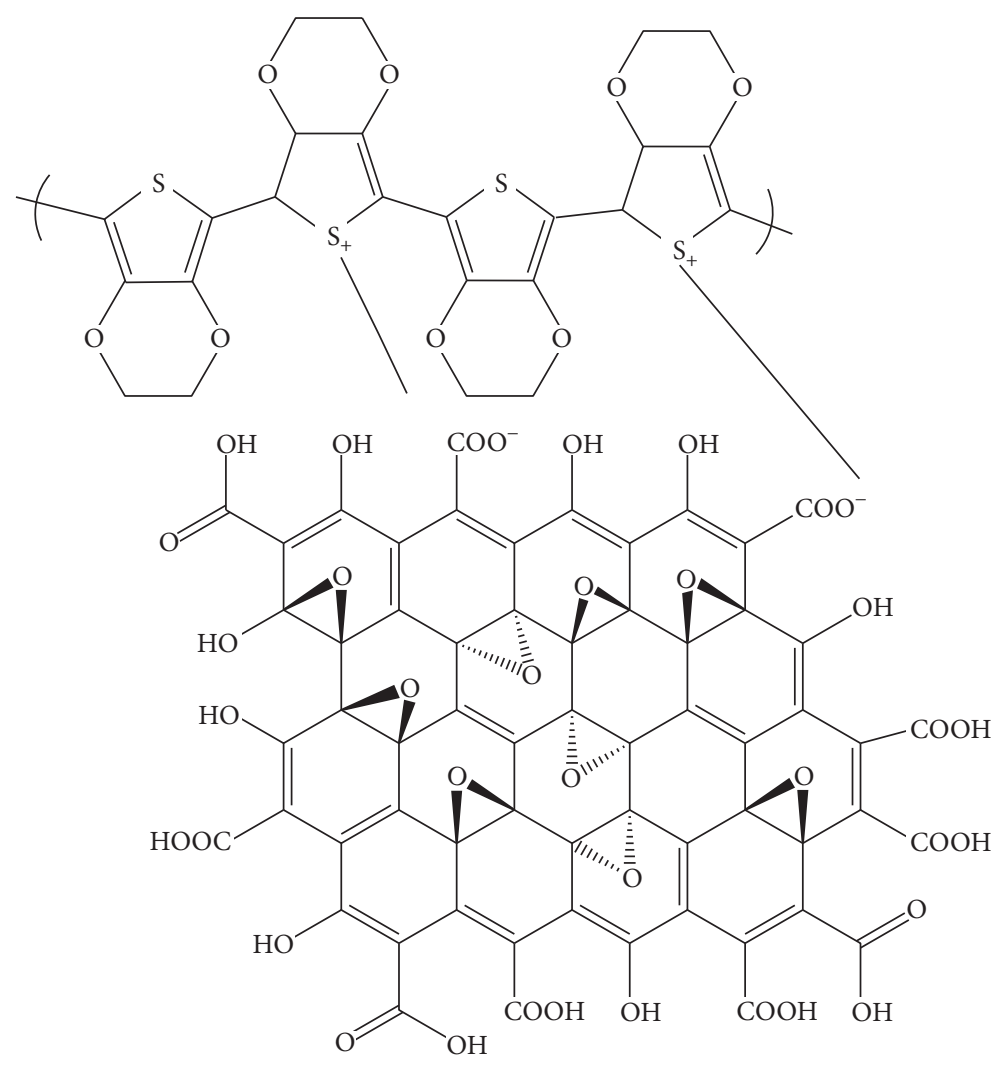

FIgURE 1: The interaction between poly(3,4-ethylenedioxythiophene) (PEDOT) and graphene oxide (GO).

the carbon-based materials [11]. Porous electrode materials help the penetration of electrolyte and improve the masscharge transfer between the electrolyte and electrode interface, thus enhancing the supercapacitive performance [12]. Nevertheless, EDLC suffers from low energy density. Pseudocapacitor yet can store more energy than EDLC but suffers from low cyclic stability and power density [13]. Hence, both EDLC and pseudocapacitor materials can be incorporated together to form hybrid composites that can enhance the performance of supercapacitor through the high surface area, porosity, and electrical conductivity provided by the carbonbased materials and CPs. In comparison to EDLC and pseudocapacitor, hybrid supercapacitor has better cycling stability and relatively large storage capacity [14].

One of the promising CPs for supercapacitor is poly(3,4ethylenedioxythiophene) (PEDOT) (Figure 1), which can be polymerized from 3,4-ethylenedioxythiophene (EDOT) monomer via electrochemical or chemical method that has high conductivity ranging from $10^{-2}$ to $10^{-5} \mathrm{~S} / \mathrm{cm}$ [15]. However, EDOT has poor solubility [16]. This major problem can be overcome by introducing an anionic dopant, that is, graphene oxide (GO), a carbon-based material that can improve the solubility of EDOT monomer [17] and simultaneously can increase the performance of the supercapacitor [18]. GO is a derivative of graphene that consists of hydrophilic functional groups, that is, hydroxyl, carboxyl, and epoxide [3].

In recent times, preparations of CPs hybrid with carbonbased materials for supercapacitors have extensively been conducted in order to fulfill the requirement of the high-performance supercapacitor. One-step electrodeposition of sulfonated graphene/polypyrrole (s-G/PPy) composite has been successfully prepared and exhibited a specific capacitance of $310 \mathrm{Fg}^{-1}$ and ability to retain $71 \%$ of its original specific capacitance after 1500 cycles [19]. Shabani Shayeh et al. [20] prepared polyaniline/reduced graphene oxide/Au nanoparticles (PANI/rGO/AuNPs) as a supercapacitor material which yield a capacitance of $303 \mathrm{Fg}^{-1}$ and long cycle stability. $\mathrm{PPy} / \mathrm{GO}$ nanocomposite for supercapacitors has been prepared via facile electrochemical codeposition by varying the deposition time. It was found that the longer deposition time resulted in a lower value of capacitance because of the larger diffusion resistance of electrolyte ions [21]. On the other hand, multilayer graphene/PEDOT thin films have been prepared by electropolymerization method. The multilayer graphene/PEDOT thin films comprising of six graphene layers showed greatly improved capacitance compared with pure graphene/PEDOT thin films and possessed greater cycling stability [22]. In addition, rGO/PPy composite for supercapacitor was investigated by varying the amount of $\mathrm{GO}$ precursor and it is found that $6 \mathrm{mg} / \mathrm{mL}$ GO precursor exhibits the highest specific capacitance. The result shows that concentration gives significant effect on the composite for supercapacitor application [8].

Previously, we have reported preparation of PEDOT/GO hybrid material for supercapacitor via chronoamperometry technique at various electropolymerization potentials [23]. 
Our previous result has shown that $1.2 \mathrm{~V}$ is the optimum electropolymerization potential to prepare PEDOT/GO hybrid material for supercapacitor electrode. To the best of our knowledge, a research on the influence of the concentration of GO and electropolymerization time on the supercapacitor performance of PEDOT/GO has not been reported. Thus, in this work, PEDOT/GO hybrid materials were prepared via potentiostatic polymerization at $1.2 \mathrm{~V}$ on indium tin oxide (ITO) substrate and the influence of the concentration of GO as a sole dopant and electropolymerization time on the performance as supercapacitor material were investigated. The capacitive performance of PEDOT/GO for supercapacitor is further investigated using cyclic voltammetry, galvanostatic charge-discharge (GCD), and electrochemical impedance spectroscopy (EIS).

\section{Experimental}

2.1. Reagents and Instrumentation. Acetone and potassium permanganate $\left(\mathrm{KMnO}_{4}\right)$ were obtained from Systerm. Methanol was purchased from $\mathrm{HmbG}$ whereas potassium chloride $(\mathrm{KCl})$ and 3,4-ethylenedioxythiophene (EDOT) monomer were obtained from Sigma-Aldrich, respectively. Graphite flake was acquired from Ashbury Inc. Phosphoric acid $\left(\mathrm{H}_{3} \mathrm{PO}_{4}\right)$, sulphuric acid $\left(\mathrm{H}_{2} \mathrm{SO}_{4}\right)$, and hydrogen peroxide $\left(\mathrm{H}_{2} \mathrm{O}_{2}\right)$ were attained from Merck. All electrochemical measurements in this work were conducted by means of three-electrode system using an Autolab M101 potentiostat equipped with NOVA software. The Pt coiled wire was used as counter electrode whereas $\mathrm{Ag} / \mathrm{AgCl}$ was employed as reference electrodes. The working electrode used was indium tin oxide (ITO) glass $\left(1 \mathrm{~cm}^{2}\right)$. The capacitive performance of PEDOT/GO composites for supercapacitor was investigated using cyclic voltammetry where the potential range applied was $-0.5 \mathrm{~V}$ to $0.5 \mathrm{~V}$, galvanostatic charge-discharge (GCD) was with various current densities $(0.3 \mathrm{~A} / \mathrm{g}$ to $2.0 \mathrm{~A} / \mathrm{g})$, and electrochemical impedance spectroscopy (EIS) at opencircuit potential (OCP) was with AC amplitude of $5 \mathrm{mV}$ in the frequency range $0.1 \mathrm{~Hz}$ to $100 \mathrm{kHz}$. The morphology of the PEDOT/GO composites was studied using field emission scanning electron microscope (FESEM, JEOL JSM-7600F).

2.2. Preparation of PEDOT/GO. GO was synthesized via Hummer's method [23]. Solutions containing $10 \mathrm{mM}$ of EDOT and different concentrations of GO, that is, $0.5,1.0$, 1.5 , and $2.0 \mathrm{mg} / \mathrm{mL}$, were prepared in deionized (DI) water $\left(18.2 \mathrm{M} \Omega \cdot \mathrm{cm}\right.$ at $\left.25^{\circ} \mathrm{C}\right)$. The EDOT containing GO solution was electropolymerized potentiostatically on ITO substrate at $1.2 \mathrm{~V}$ [23] with various electropolymerization times ranging from 1 to $30 \mathrm{~min}$.

\section{Results and Discussion}

3.1. Morphology. The surface morphology of PEDOT/GO with different concentrations of GO and electropolymerization times was studied using FESEM. The FESEM images of PEDOT/GO prepared from different concentrations of GO at $10 \mathrm{~min}$ are presented in Figure 2. The FESEM images of PEDOT/GO show a significant change with the increment of the amount of GO in which the wrinkled paper-like sheets of GO become more prominent and thicker. The PEDOT/GO with the maximum content of GO, that is, $2.0 \mathrm{mg} / \mathrm{mL}$ GO (Figure 2(d)), shows the most pronounced and thickest wrinkled paper-like sheets morphology in comparison with other concentrations of GO. However, the morphology of PEDOT was not observed in all FESEM images due to the presence of large dopant ion (GO) with the anionic properties that overshadows PEDOT morphology [16].

In order to investigate the influence of electropolymerization time on the surface morphology of PEDOT/GO, FESEM was performed on PEDOT/GO prepared from $1.0 \mathrm{mg} / \mathrm{mL}$ GO at different electropolymerization times (Figure 3). The PEDOT/GO prepared at various times likewise shows the typical wrinkled paper-like sheets morphology similarly when the GO amount increases. The wrinkled paper-like sheets' morphology of PEDOT/GO grows larger and resulted in more dense and prominent morphology as the electropolymerization time prolongs.

\subsection{Cyclic Voltammetry}

3.2.1. Effect of GO Concentration. The capacitive properties of PEDOT/GO prepared from different concentrations of GO at 10 minutes were studied using cyclic voltammetry in $1.0 \mathrm{M} \mathrm{H}_{2} \mathrm{SO}_{4}$. The cyclic voltammograms (CVs) of PEDOT/GO with 0.5 and $1.0 \mathrm{mg} / \mathrm{mL} \mathrm{GO} \mathrm{(Figure} \mathrm{4(a))} \mathrm{show}$ broad quasirectangular shape with wave-like properties as a result of large double-layer capacitance provided by GO, that is, a carbon-based material $[24,25]$ whereas CVs of PEDOT/GO with 1.5 and $2.0 \mathrm{mg} / \mathrm{mL}$ GO show oblique and narrow shape, demonstrating a large interfacial contact resistance with the bulk electrolyte and low ionic propagation behavior of the PEDOT/GO. Generally, the integrated area of the $\mathrm{CV}$ of PEDOT/GO decreases with the increasing amount of GO. However, the CV integrated area of PEDOT/GO with $1.0 \mathrm{mg} / \mathrm{mL}$ amount of GO is higher than PEDOT/GO containing $0.5 \mathrm{mg} / \mathrm{mL} \mathrm{GO}$, indicating increase in electrical double-layer (EDL) capacitance due to the abundance amount of GO [25]. The large surface area of GO provides a more electroactive site for electrochemical reaction [21].

The CV integrated areas of PEDOT/GO composites were further investigated by calculating the specific capacitance $\left(C_{\text {sp }}\right)$ and the ability of a system to store energy using

$$
C_{\mathrm{sp}}=\frac{\int i d V}{v \Delta V m},
$$

where $\int i d V$ is the integrated area of the $\mathrm{CV}, v$ denotes the scan rate $(\mathrm{V} / \mathrm{s}), \Delta V$ is the range of potential applied $(\mathrm{V})$, and $m$ is the mass of the electrode material (g). The calculated values of specific capacitance versus concentration of GO are plotted and depicted in Figure 4(b). The specific capacitance of PEDOT/GO with $0.5 \mathrm{mg} / \mathrm{mL} \mathrm{GO}$ is $75.34 \mathrm{~F} / \mathrm{g}$. As the GO concentration increases to $1 \mathrm{mg} / \mathrm{mL}$, the specific capacitance obtained is $157.17 \mathrm{~F} / \mathrm{g}$, which is the maximum value of specific capacitance in this study. This could be due to the synergistic effect of the high conductivity of PEDOT and large surface area of GO. As the amount of GO increases, a larger surface 


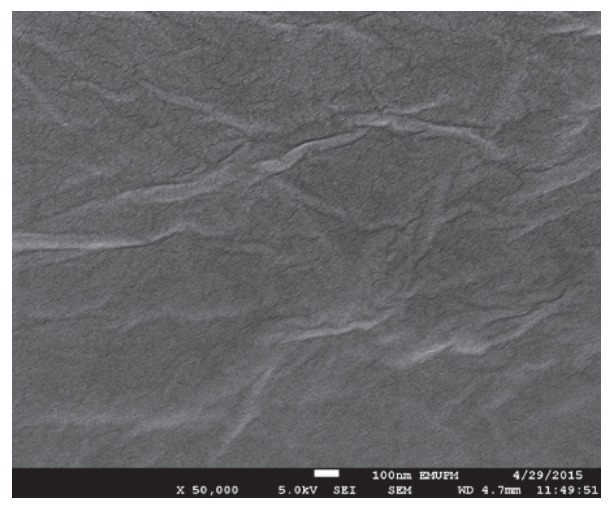

(a)

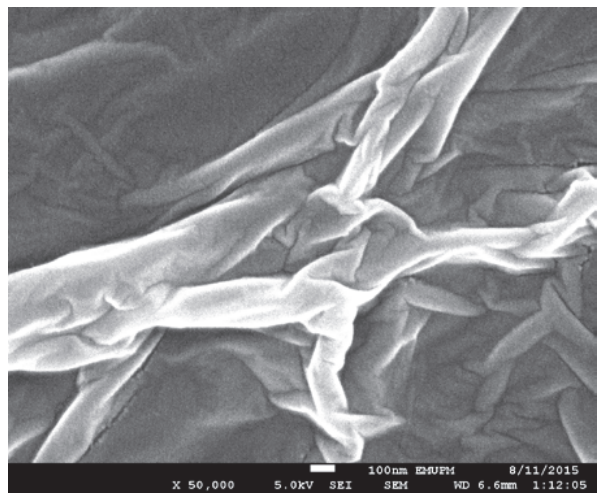

(c)

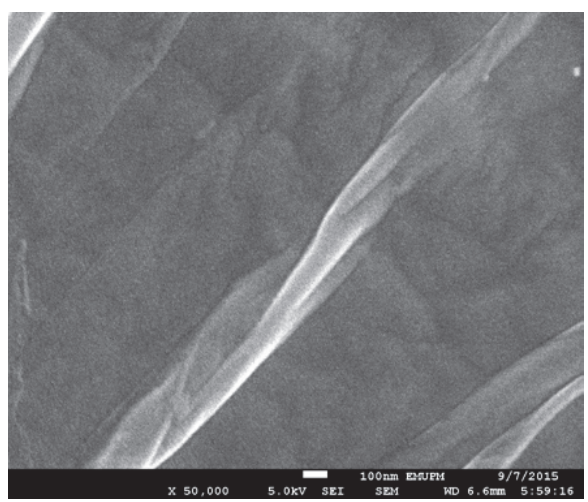

(b)

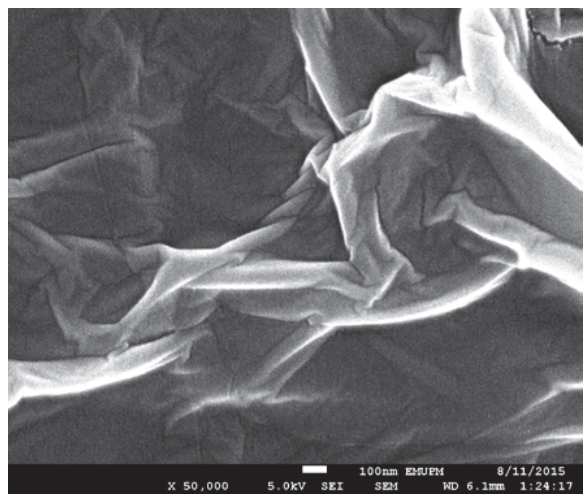

(d)

Figure 2: FESEM images of PEDOT/GO prepared from different concentrations of GO: (a) $0.5 \mathrm{mg} / \mathrm{mL}$, (b) $1.0 \mathrm{mg} / \mathrm{mL}$, (c) $1.5 \mathrm{mg} / \mathrm{mL}$, and (d) $2.0 \mathrm{mg} / \mathrm{mL}$.

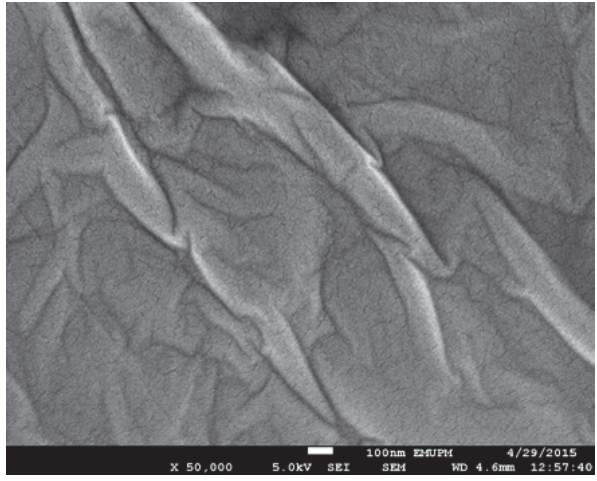

(a)

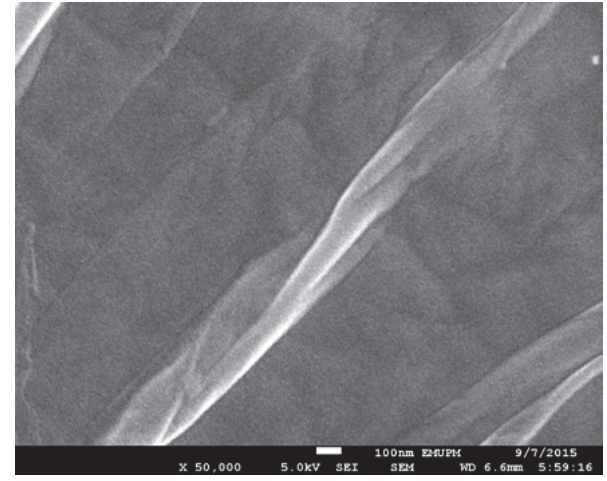

(b)

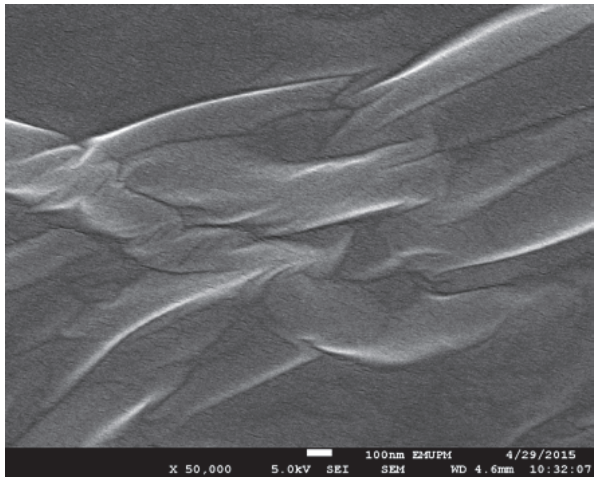

(c)

FIGURE 3: FESEM images of PEDOT/GO prepared at different electropolymerization times: (a) $1 \mathrm{~min}$, (b) $10 \mathrm{~min}$, and (c) $30 \mathrm{~min}$. 


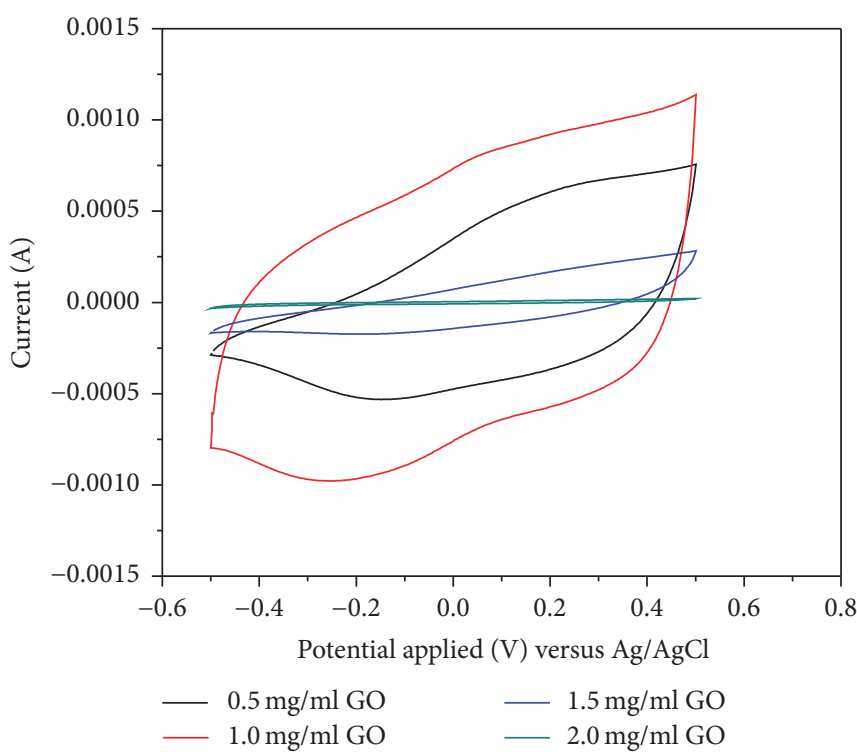

(a)

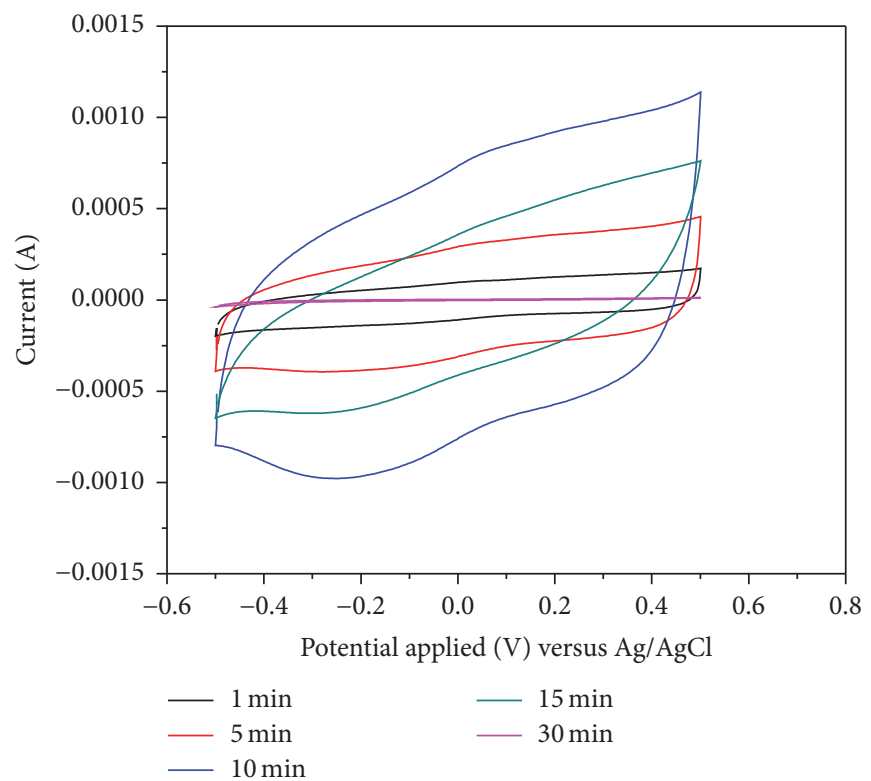

(c)

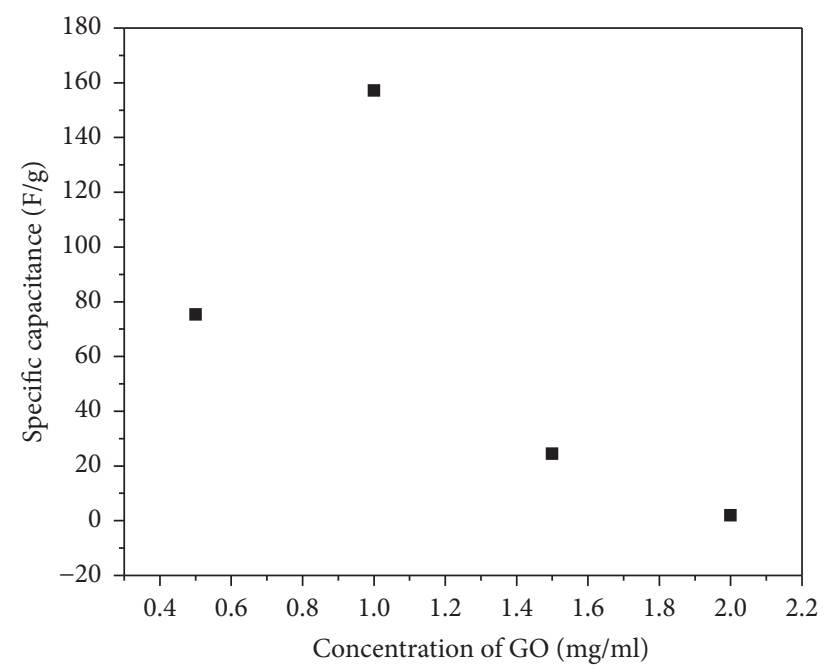

(b)

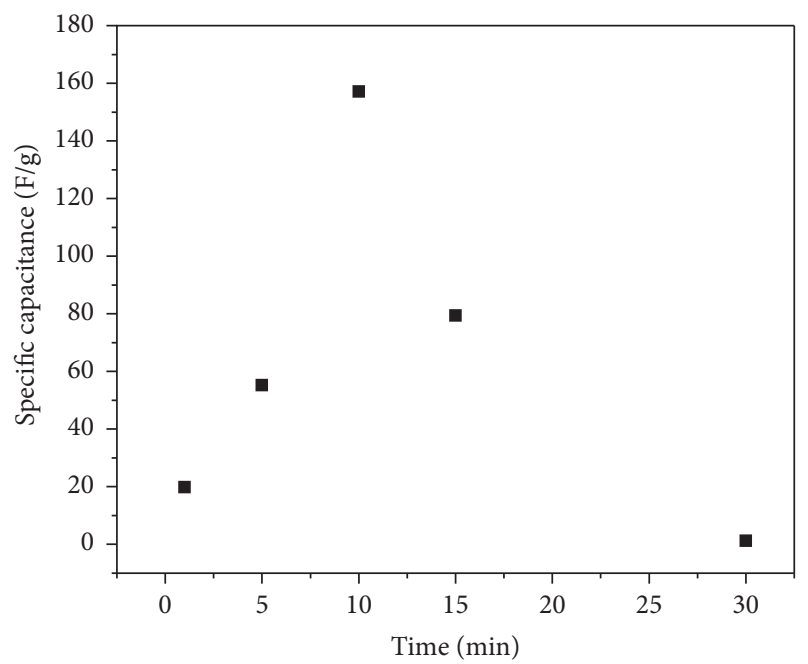

(d)

Figure 4: (a) CVs of PEDOT/GO and (b) specific capacitance of PEDOT/GO for different concentrations of GO ((i) $0.5 \mathrm{mg} / \mathrm{mL}$, (ii) $1.0 \mathrm{mg} / \mathrm{mL}$, (iii) $1.5 \mathrm{mg} / \mathrm{mL}$, and (iv) $2.0 \mathrm{mg} / \mathrm{mL}$ ). (c) CVs of PEDOT/GO and (d) specific capacitance of PEDOT/GO at different electropolymerization times ((i) $1 \mathrm{~min}$, (ii) $5 \mathrm{~min}$, (iii) $10 \mathrm{~min}$, (iv) $15 \mathrm{~min}$, and (v) $30 \mathrm{~min}$ ). Scan rate: $0.1 \mathrm{~V} / \mathrm{s}$.

area provided by GO will make more interaction between the electrode and electrolyte interface that allows high accessibility of electrolyte ions [26]. However, as the amount of GO increases to 1.5 and $2.0 \mathrm{mg} / \mathrm{mL} \mathrm{GO}$ (very high concentration), the specific capacitances decrease to $24.45 \mathrm{~F} / \mathrm{g}$ and $1.96 \mathrm{~F} / \mathrm{g}$, respectively. This might be due to the nonconductive behavior of GO [13] that makes the layer become less conductive at the very high amount of GO and eventually the transfer of electrons between the interface of electrolyte and electrode is partially blocked. In addition, the electrical conductivity of PEDOT/GO decreases with the high amount of GO due to the low electrical conductivity of GO which causes the value of specific capacitance to decrease [27]. The results show that optimum amount of GO is very important to obtain good capacitive properties and high specific capacitance value.

3.2.2. Effect of Electropolymerization Time. The capacitive properties of PEDOT/GO with the maximum specific capacitance value which is PEDOT/GO containing $1.0 \mathrm{mg} / \mathrm{mL}$ GO was further studied using cyclic voltammetry at different electropolymerization times. From Figure 4(c), the CVs of PEDOT/GO electropolymerized at 1, 5, and $10 \mathrm{~min}$ exhibit quasirectangular shape. In contrast, $\mathrm{CVs}$ of PEDOT/GO electropolymerized at 15 and $30 \mathrm{~min}$ show oblique and narrow shapes, respectively. As the electropolymerization time is increased from 1 to $5 \mathrm{~min}$, the $\mathrm{CV}$ integrated area 


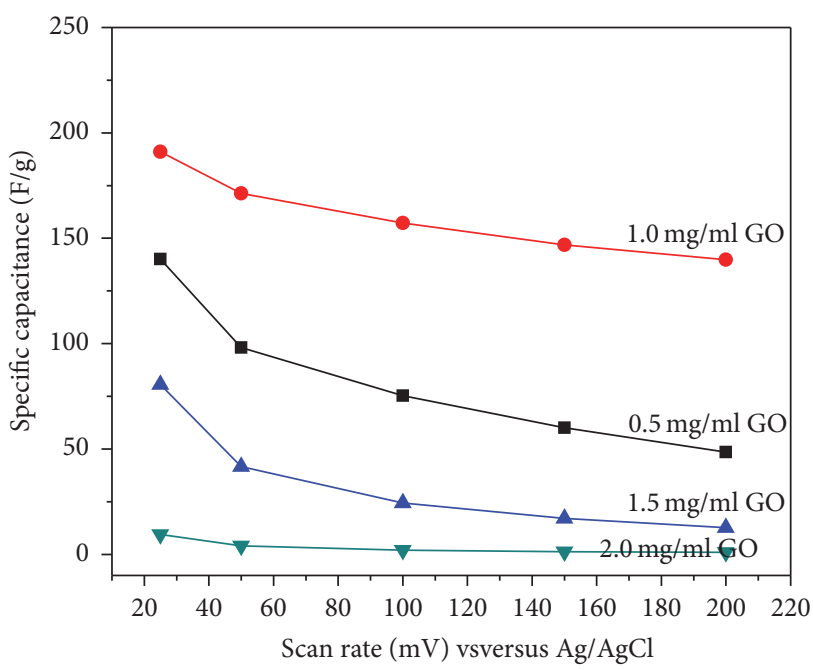

(a)

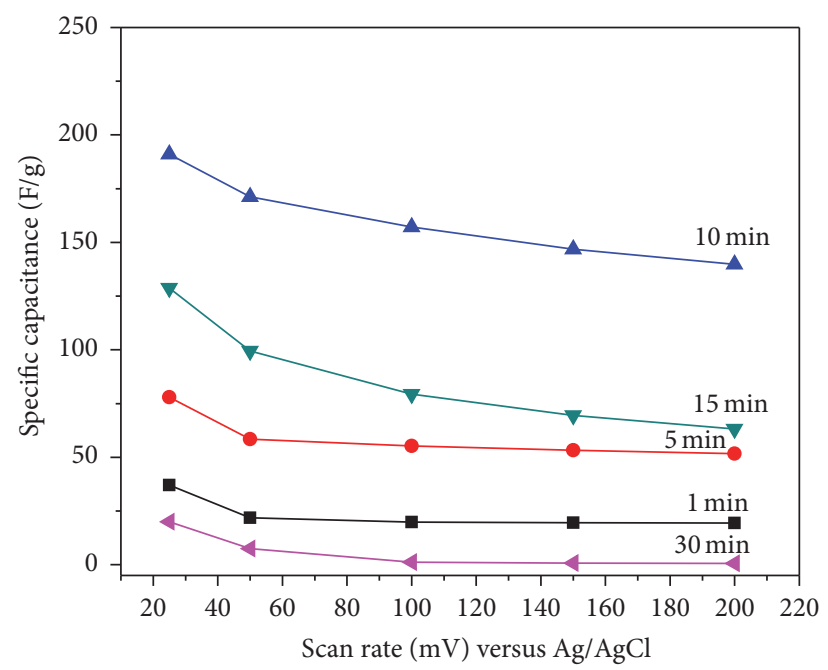

(b)

FIGURE 5: Specific capacitance of PEDOT/GO for (a) different concentrations of GO and (b) different electropolymerization times at different scan rates $(25 \mathrm{mV} / \mathrm{s}, 50 \mathrm{mV} / \mathrm{s}, 100 \mathrm{mV} / \mathrm{s}, 150 \mathrm{mV} / \mathrm{s}$, and $200 \mathrm{mV} / \mathrm{s})$ in $1.0 \mathrm{M} \mathrm{H}_{2} \mathrm{SO}_{4}$.

of PEDOT/GO becomes larger. When the electropolymerization time increases to $10 \mathrm{~min}$, a maximum CV integrated area is obtained. Nevertheless, the CV integrated area shrinks when the electropolymerization time is raised to $15 \mathrm{~min}$. This phenomenon becomes more pronounced as the electropolymerization time is further increased to $30 \mathrm{~min}$.

The specific capacitance values obtained for PEDOT/GO with different electropolymerization time is depicted in Figure 4(d). As the electropolymerization time increases from 1 to $5 \mathrm{~min}$, the specific capacitance increases, which is from 19.87 to $55.25 \mathrm{~F} / \mathrm{g}$. The specific capacitance rises tremendously to $157.17 \mathrm{~F} / \mathrm{g}$ as the electropolymerization time increases to $10 \mathrm{~min}$, where the maximum value of specific capacitance is obtained. However, the specific capacitances decline as the electropolymerization time increases to 15 and $30 \mathrm{~min}$ with specific capacitances of 79.44 and $1.21 \mathrm{~F} / \mathrm{g}$, respectively. The decreasing values of specific capacitance may due to the longer electropolymerization time that causes the polymer chains to grow instead of forming a new chain. Thus, this makes the electrolyte ions difficult to penetrate due to the elongation and thickening of the polymer chains which reduce the ability of charge storage of the PEDOT/GO composite [26]. This phenomenon can be clearly seen in the FESEM images of PEDOT/GO in which the wrinkled paper-like sheet becomes more prominent and dense as the electropolymerization time increases (Figure 3).

3.2.3. Effect of Scan Rate. The effect of scan rate on the specific capacitance of PEDOT/GO was performed via cyclic voltammetry measurements. The specific capacitance of PEDOT/GO at different scan rates $(25,50,100,150$, and $200 \mathrm{mV} / \mathrm{s}$ ) with different concentrations of $\mathrm{GO}$ and different electropolymerization times is displayed in Figures 5(a) and 5(b), respectively. The specific capacitances decrease with the increasing of scan rate due to the ineffective interaction between the electrode materials and electrolyte during the

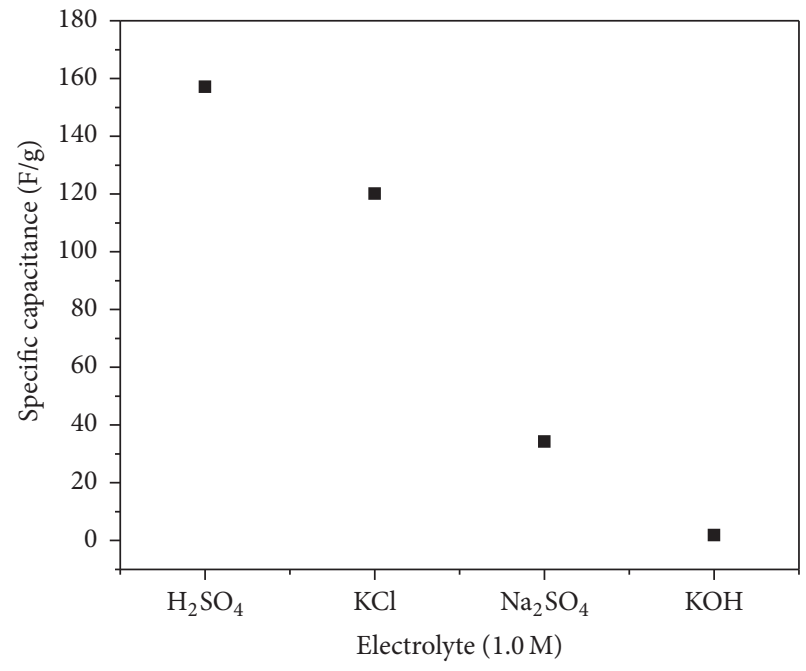

FIGURE 6: The specific capacitance of PEDOT/GO with $1.0 \mathrm{mg} / \mathrm{mL}$ $\mathrm{GO}$ electropolymerized for 10 minutes in $1.0 \mathrm{M}$ of different electrolytes $\left(\mathrm{H}_{2} \mathrm{SO}_{4}, \mathrm{KCl}, \mathrm{Na}_{2} \mathrm{SO}_{4}\right.$, and $\left.\mathrm{KOH}\right)$. Scan rate: $100 \mathrm{mV} / \mathrm{s}$.

fast CV scan [21]. During the slow CV scan rate, the specific capacitance increases greatly as a result of the slow ion diffusion from the electrolyte into the electrode materials which maximizes the interaction of electrode materials and the electrolyte [21].

3.2.4. Effect of Different Electrolytes on Specific Capacitance. The capacitive behavior of PEDOT/GO was further investigated by studying the effect of different electrolytes on the value of specific capacitance as the interaction of electrolyte and the electrode materials also plays a crucial part in the supercapacitor performance. Electrolyte provides ionic conductivity and assists in the compensation of charge on each of the electrodes [28]. Figure 6 shows that the maximum specific 


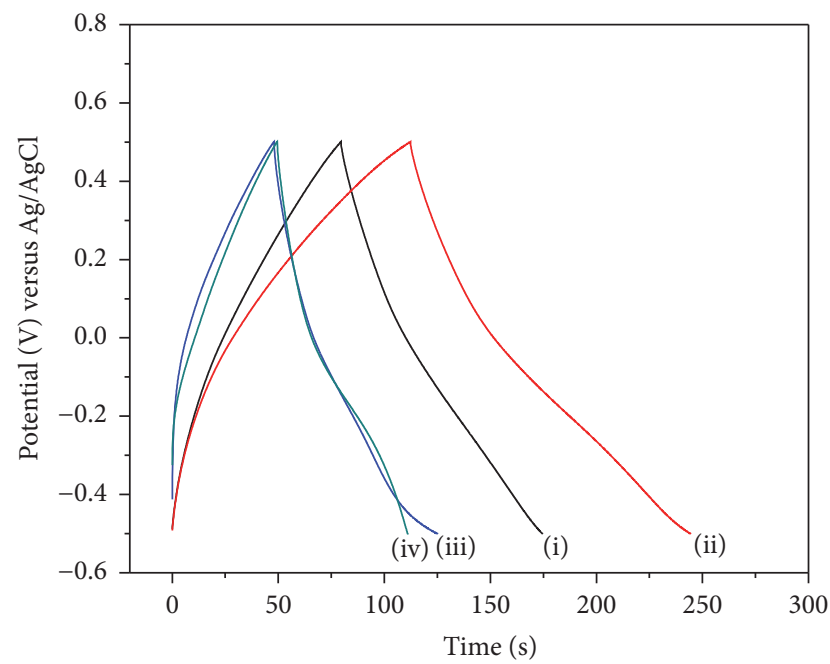

(i) $0.5 \mathrm{mg} / \mathrm{ml} \mathrm{GO}$ (ii) $1.0 \mathrm{mg} / \mathrm{ml} \mathrm{GO}$ (iii) $1.5 \mathrm{mg} / \mathrm{ml} \mathrm{GO}$

(iv) $2.0 \mathrm{mg} / \mathrm{ml} \mathrm{GO}$

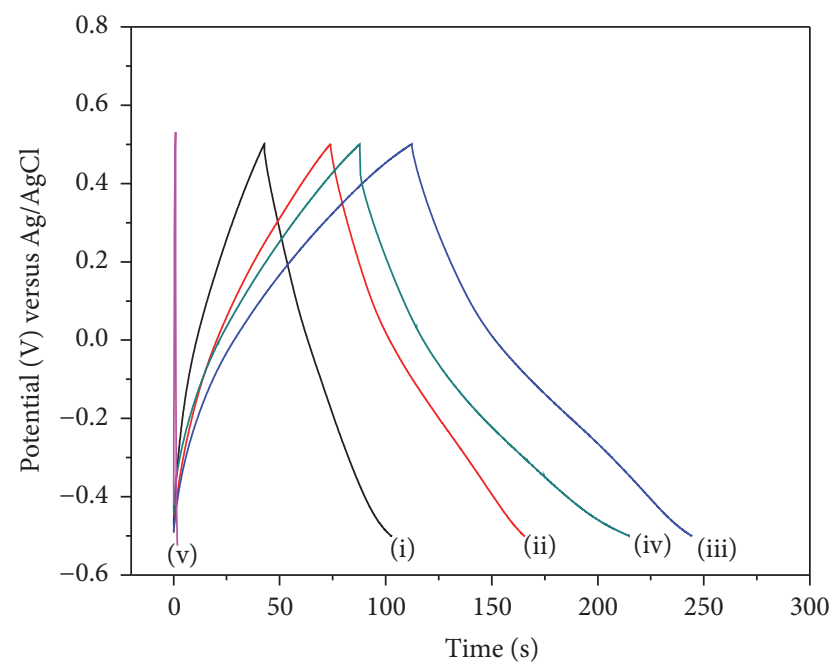

- (i) $1 \mathrm{~min}$ (ii) $5 \mathrm{~min}$ (iii) $10 \mathrm{~min}$

(a)

(b)

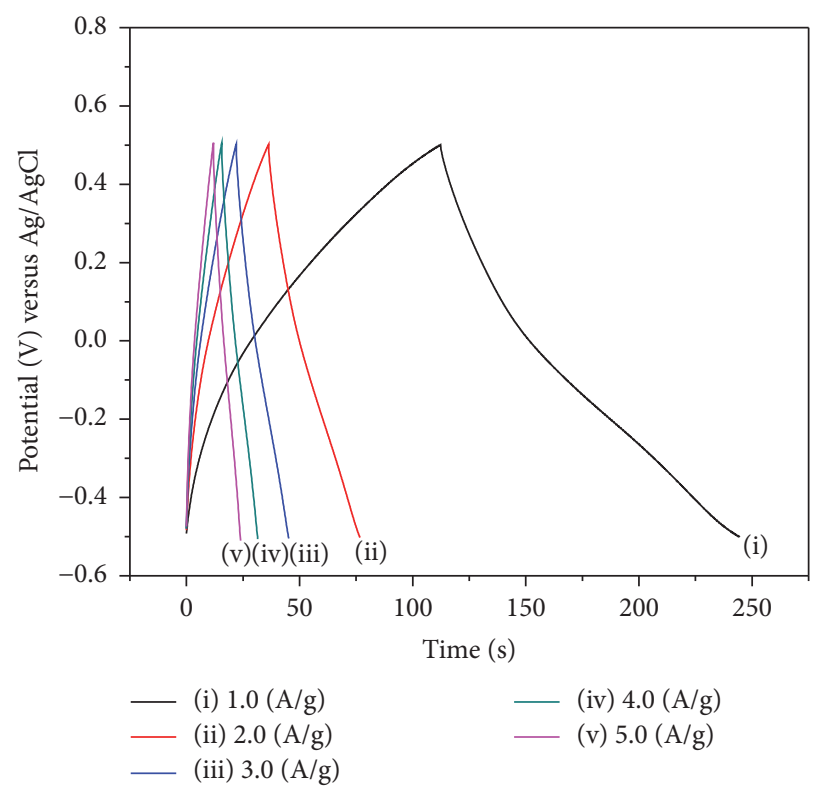

(c)

FIGURE 7: GCD curves of PEDOT/GO (a) electropolymerized at $1.2 \mathrm{~V}$ and $10 \mathrm{~min}$ with different concentrations of GO $(0.5 \mathrm{mg} / \mathrm{mL}, 1.0 \mathrm{mg} / \mathrm{mL}$, $1.5 \mathrm{mg} / \mathrm{mL}$, and $2.0 \mathrm{mg} / \mathrm{mL}$ ), (b) electropolymerized at $1.2 \mathrm{~V}$ containing $1.0 \mathrm{mg} / \mathrm{mL} \mathrm{GO}$ with different electropolymerization times (1 min, $5 \mathrm{~min}, 10 \mathrm{~min}, 15 \mathrm{~min}$, and $30 \mathrm{~min}$ ), (c) electropolymerized at $1.2 \mathrm{~V}$ and 10 minutes containing $1.0 \mathrm{mg} / \mathrm{mL}$ GO with different current densities $(1.0 \mathrm{~A} / \mathrm{g}, 2.0 \mathrm{~A} / \mathrm{g}, 3.0 \mathrm{~A} / \mathrm{g}, 4.0 \mathrm{~A} / \mathrm{g}$, and $5.0 \mathrm{~A} / \mathrm{g})$.

capacitance is obtained in $\mathrm{H}_{2} \mathrm{SO}_{4}(157.17 \mathrm{~F} / \mathrm{g})$ followed by $\mathrm{KCl}, \mathrm{Na}_{2} \mathrm{SO}_{4}$, and $\mathrm{KOH}$ with the specific capacitances of $120.13,34.24$, and $1.86 \mathrm{~F} / \mathrm{g}$, respectively. This is due to the high conductivity of $\mathrm{H}_{2} \mathrm{SO}_{4}\left(\sim 0.8 \mathrm{~S} / \mathrm{cm}^{2}\right.$ at $\left.25^{\circ} \mathrm{C}\right)$ compared to other electrolytes [28].

3.3. Galvanostatic Charge-Discharge (GCD). Figures 7(a) and 7(b) demonstrate the GCD profile of PEDOT/GO containing different amounts of $\mathrm{GO}$ and different electropolymerization times at $1.0 \mathrm{~A} / \mathrm{g}$ current density. The PEDOT/GO containing
$1.0 \mathrm{mg} / \mathrm{mL}$ GO displays the longest discharge time which extends to $132.2 \mathrm{~s}$. Figure 7 (c) presents the GCD profile of PEDOT/GO with the longest discharge time containing $1.0 \mathrm{mg} / \mathrm{mL}$ GO electropolymerized for $10 \mathrm{~min}$ at different current densities. The discharge time of PEDOT/GO at high current density drops which is attributable to the fast charge and discharge cycle which reduce the accessibility and diffusion of electrolyte ions into the electrode active materials [7]. All the GCD curves exhibit equilateral triangle shape demonstrating high reversibility during the charge/discharge processes 
TABLE 1: The values of $R_{\mathrm{ct}}$, ESR, and $\chi^{2}$ and electrical circuit of PEDOT and PEDOT/GO containing $1.0 \mathrm{mg} / \mathrm{mL}$ GO electropolymerized for 10 minutes.

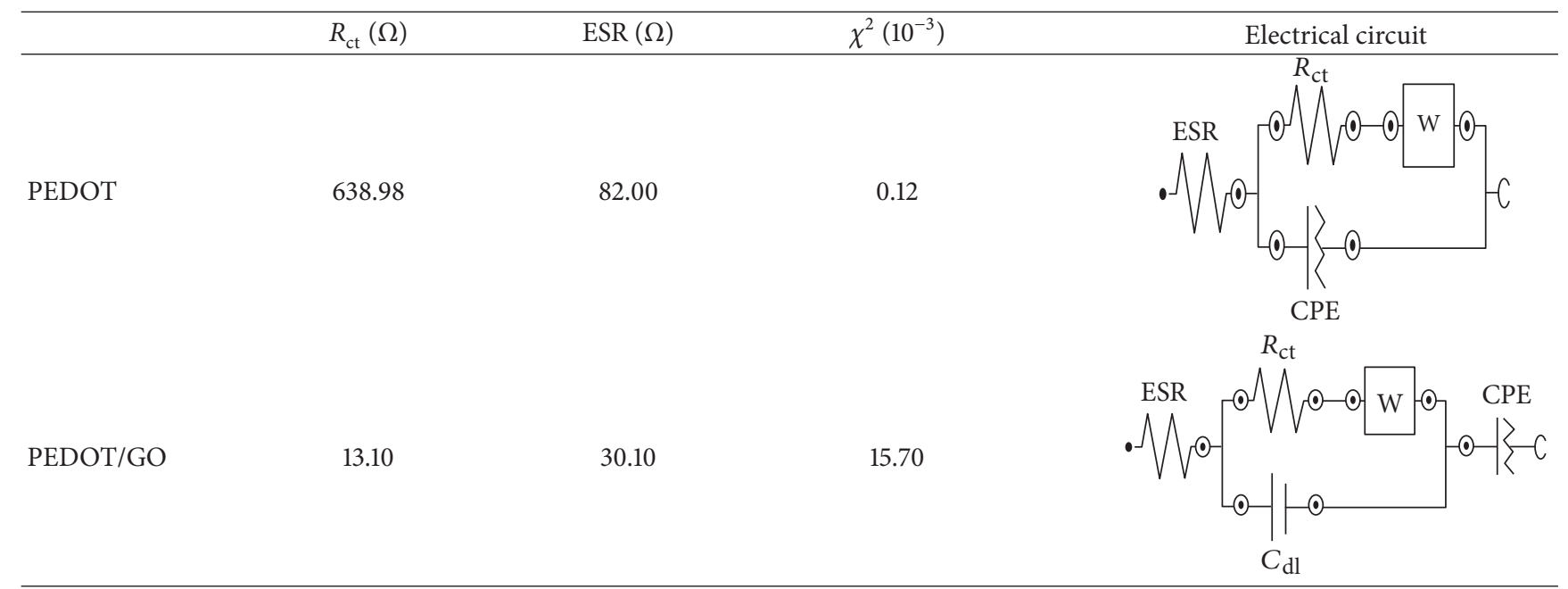

$[24,29]$. From the GCD profile of PEDOT/GO, there is no IR drop occurring for all current densities, indicating that electrodes have low internal resistance. The presence of IR drop is not good for energy storage devices as there will be a lot of energy loss during the charging-discharging process [21]. From the GCD, the highest energy and power density acquired are $18.24 \mathrm{~W} / \mathrm{kg}$ and $496.64 \mathrm{Wh} / \mathrm{kg}$, respectively, at a current density of $1.0 \mathrm{~A} / \mathrm{g}$ for PEDOT electropolymerized in $1.0 \mathrm{mg} / \mathrm{mL} \mathrm{GO}$ for $10 \mathrm{~min}$.

3.4. Electrochemical Impedance Spectroscopy (EIS). EIS measurements were performed to study the resistance of charge transfer $\left(R_{\mathrm{ct}}\right)$ and ion diffusion. At the high-frequency region of the Nyquist plot in which the $R_{\mathrm{ct}}$ is acquired from the diameter of a semicircle describes the charge transfer resistance occurs at the interface of electrode and electrolyte [26]. From Figure 8 , PEDOT shows large semicircle with the $R_{\mathrm{ct}}$ value of $638.98 \Omega$ (Table 1). Large semicircle demonstrates that PEDOT has high interfacial resistance with poor behavior of charge propagation [25]. The diameter of the semicircle reduces significantly after GO is introduced into PEDOT with the $R_{\mathrm{ct}}$ value of $13.10 \Omega$, indicating that PEDOT/GO has better charge propagation behavior and low interfacial resistance in comparison to PEDOT. The equivalent series resistance (ESR) is obtained at the intercept of the real axis at the highfrequency region of the Nyquist plot which is related to the internal resistance of the electrode and the total resistance of solution resistance $[26,29]$. The ESR value of PEDOT/GO $(30.10 \Omega)$ is much lower in comparison to PEDOT $(82 \Omega)$.

The ion diffusion behavior between the electrode and electrolyte was examined from the slope at the low-frequency region of the Nyquist plot. The Warburg slope of PEDOT/GO exhibits more vertical line compared to PEDOT indicating that PEDOT/GO has better capacitive behavior. The Nyquist plots of both PEDOT and PEDOT/GO were fitted to construct equivalent electrical circuits (Table 1) to represent the electrochemical system of the composites. The equivalent electrical circuits proposed for PEDOT and PEDOT/GO

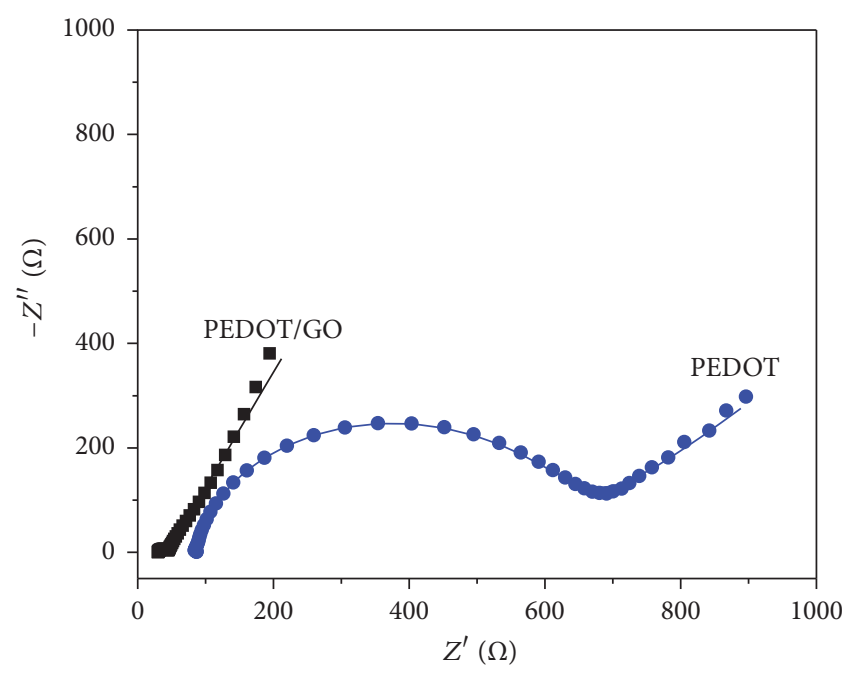

FIgUre 8: Nyquist plots of PEDOT and PEDOT/GO containing $1.0 \mathrm{mg} / \mathrm{mL}$ of GO electropolymerized for $10 \mathrm{~min}$ in $1.0 \mathrm{M} \mathrm{H}_{2} \mathrm{SO}_{4}$. Experimental data (dotted line) and fitted data based on equivalent circuit (solid line).

involve ESR, resistance of charge transfer $\left(R_{\mathrm{ct}}\right)$, constant phase element $(\mathrm{CPE})$, double-layer capacitance $\left(C_{\mathrm{dl}}\right)$, and Warburg $(W)$. The CPE is used to represent the inhomogeneity of the electrode surface. Low average error $\left(\chi^{2}\right)$ denotes that the equivalent electrical circuits are suitable with the electrochemical system of PEDOT and PEDOT/GO.

\section{Conclusion}

PEDOT/GO composites for supercapacitor electrode material have been successfully prepared using potentiostatic electropolymerization. The capacitive properties of PEDOT/GO are greatly influenced by the electropolymerization time, the amount of the GO precursor, and the type of electrolyte. The maximum specific capacitance can be obtained with the 
optimum and adequate electropolymerization time and concentration of GO precursor as longer electropolymerization time and too much of GO lead to the loss of the specific capacitance and the performance of the supercapacitor. The high amount of GO partially blocks the electron transfer between electrode material and electrolyte and eventually minimizes the electrochemical reaction.

\section{Competing Interests}

The authors declare that there is no conflict of interests regarding the publication of this paper.

\section{Acknowledgments}

This work is supported by Research Grant Scheme (01-02-131388FR) from the Ministry of Education, Malaysia.

\section{References}

[1] J. Wang, Y. Xu, J. Zhu, and P. Ren, "Electrochemical in situ polymerization of reduced graphene oxide/polypyrrole composite with high power density," Journal of Power Sources, vol. 208, pp. 138-143, 2012.

[2] H. Pan, J. Li, and Y. P. Feng, "Carbon nanotubes for supercapacitor," Nanoscale Research Letters, vol. 5, article 654, 2010.

[3] Q. Zhang, Y. Li, Y. Feng, and W. Feng, "Electropolymerization of graphene oxide/polyaniline composite for high-performance supercapacitor," Electrochimica Acta, vol. 90, pp. 95-100, 2013.

[4] G. A. Snook, P. Kao, and A. S. Best, "Conducting-polymerbased supercapacitor devices and electrodes," Journal of Power Sources, vol. 196, no. 1, pp. 1-12, 2011.

[5] A. K. Sarker and J.-D. Hong, "Electrochemical reduction of ultrathin graphene oxide/polyaniline films for supercapacitor electrodes with a high specific capacitance," Colloids and Surfaces A: Physicochemical and Engineering Aspects, vol. 436, pp. 967-974, 2013.

[6] B. E. Conway, Electrochemical Supercapacitors Scientific Fundamentals and Technological Applications, Kluwer Academic/ Plenum, New York, NY, USA, 1999.

[7] R. Yuksel, C. Durucan, and H. E. Unalan, "Ternary nanocomposite SWNT/ $\mathrm{WO}_{3} / \mathrm{PANI}$ thin film electrodes for supercapacitors," Journal of Alloys and Compounds, vol. 658, pp. 183-189, 2016.

[8] H.-H. Chang, C.-K. Chang, Y.-C. Tsai, and C.-S. Liao, "Electrochemically synthesized graphene/polypyrrole composites and their use in supercapacitor," Carbon, vol. 50, no. 6, pp. 23312336, 2012.

[9] B. E. Conway and W. G. Pell, "Double-layer and pseudocapacitance types of electrochemical capacitors and their applications to the development of hybrid devices," Journal of Solid State Electrochemistry, vol. 7, no. 9, pp. 637-644, 2003.

[10] Z.-Y. Li, M. S. Akhtar, and O.-B. Yang, "Supercapacitors with ultrahigh energy density based on mesoporous carbon nanofibers: enhanced double-layer electrochemical properties," Journal of Alloys and Compounds, vol. 653, pp. 212-218, 2015.

[11] Z. Zhao, G. F. Richardson, Q. Meng, S. Zhu, H.-C. Kuan, and J. Ma, "PEDOT-based composites as electrode materials for supercapacitors," Nanotechnology, vol. 27, no. 4, Article ID 042001, 2015.
[12] G. Zhu, J. Yang, Y. Liu et al., "Porous Fe-Mn-O nanocomposites: synthesis and supercapacitor electrode application," Progress in Natural Science: Materials International, vol. 26, no. 3, pp. 264270, 2016.

[13] H.-J. Choi, S.-M. Jung, J.-M. Seo, D. W. Chang, L. Dai, and J.B. Baek, "Graphene for energy conversion and storage in fuel cells and supercapacitors," Nano Energy, vol. 1, no. 4, pp. 534551, 2012.

[14] D. Jacob, P. A. Mini, A. Balakrishnan, S. V. Nair, and K. R. V. Subramanian, "Electrochemical behaviour of graphene-poly (3,4-ethylenedioxythiophene) (PEDOT) composite electrodes for supercapacitor applications," Bulletin of Materials Science, vol. 37, no. 1, pp. 61-69, 2014.

[15] J. Hwang, F. Amy, and A. Kahn, "Spectroscopic study on sputtered PEDOT Â•PSS: role of surface PSS layer," Organic Electronics, vol. 7, no. 5, pp. 387-396, 2006.

[16] S. Zhang, J. Hou, R. Zhang, J. Xu, G. Nie, and S. Pu, "Electrochemical polymerization of 3,4-ethylenedioxythiophene in aqueous solution containing N-dodecyl- $\beta$-d-maltoside," European Polymer Journal, vol. 42, no. 1, pp. 149-160, 2006.

[17] K. Zhang, J. Xu, X. Zhu et al., "Poly(3,4-ethylenedioxythiophene) nanorods grown on graphene oxide sheets as electrochemical sensing platform for rutin," Journal of Electroanalytical Chemistry, vol. 739, no. 1, pp. 66-72, 2015.

[18] A. Österholm, T. Lindfors, J. Kauppila, P. Damlin, and C. Kvarnström, "Electrochemical incorporation of graphene oxide into conducting polymer films," Electrochimica Acta, vol. 83, pp. 463-470, 2012.

[19] X. Zuo, Y. Zhang, L. Si et al., "One-step electrochemical preparation of sulfonated graphene/polypyrrole composite and its application to supercapacitor," Journal of Alloys and Compounds, vol. 688, pp. 140-148, 2016.

[20] J. Shabani Shayeh, A. Ehsani, M. R. Ganjali, P. Norouzi, and B. Jaleh, "Conductive polymer/reduced graphene oxide/Au nano particles as efficient composite materials in electrochemical supercapacitors," Applied Surface Science, vol. 353, pp. 594-599, 2015.

[21] H. Zhou, G. Han, Y. Xiao, Y. Chang, and H.-J. Zhai, "Facile preparation of polypyrrole/graphene oxide nanocomposites with large areal capacitance using electrochemical codeposition for supercapacitors," Journal of Power Sources, vol. 263, pp. 259267, 2014.

[22] S. Lee, M. S. Cho, H. Lee, J.-D. Nam, and Y. Lee, "A facile synthetic route for well defined multilayer films of graphene and PEDOT via an electrochemical method," Journal of Materials Chemistry, vol. 22, no. 5, pp. 1899-1903, 2012.

[23] N. H. Nabilah Azman, H. N. Lim, and Y. Sulaiman, "Effect of electropolymerization potential on the preparation of PEDOT/graphene oxide hybrid material for supercapacitor application," Electrochimica Acta, vol. 188, pp. 785-792, 2016.

[24] J. Zhang and X. S. Zhao, "Conducting polymers directly coated on reduced graphene oxide sheets as high-performance supercapacitor electrodes," Journal of Physical Chemistry C, vol. 116, no. 9, pp. 5420-5426, 2012.

[25] P. Si, S. Ding, X.-W. Lou, and D.-H. Kim, "An electrochemically formed three-dimensional structure of polypyrrole/graphene nanoplatelets for high-performance supercapacitors," RSC Advances, vol. 1, no. 7, pp. 1271-1278, 2011.

[26] Y. S. Lim, Y. P. Tan, H. N. Lim, N. M. Huang, and W. T. Tan, "Preparation and characterization of polypyrrole/graphene nanocomposite films and their electrochemical performance," Journal of Polymer Research, vol. 20, no. 6, article 156, 2013. 
[27] Y. Wu, K. Zhang, J. Xu et al., "Sensitive detection of hydroxylamine on Poly (3, 4-ethylenedioxythiophene)/graphene oxide nanocomposite electrode," International Journal of Electrochemical Science, vol. 9, pp. 6594-6607, 2014.

[28] C. Zhong, Y. Deng, W. Hu, J. Qiao, L. Zhang, and J. Zhang, "A review of electrolyte materials and compositions for electrochemical supercapacitors," Chemical Society Reviews, vol. 44, no. 21, pp. 7484-7539, 2015.

[29] C. Pan, H. Gu, and L. Dong, "Synthesis and electrochemical performance of polyaniline @ $\mathrm{MnO}_{2}$ /graphene ternary composites for electrochemical supercapacitors," Journal of Power Sources, vol. 303, pp. 175-181, 2016. 

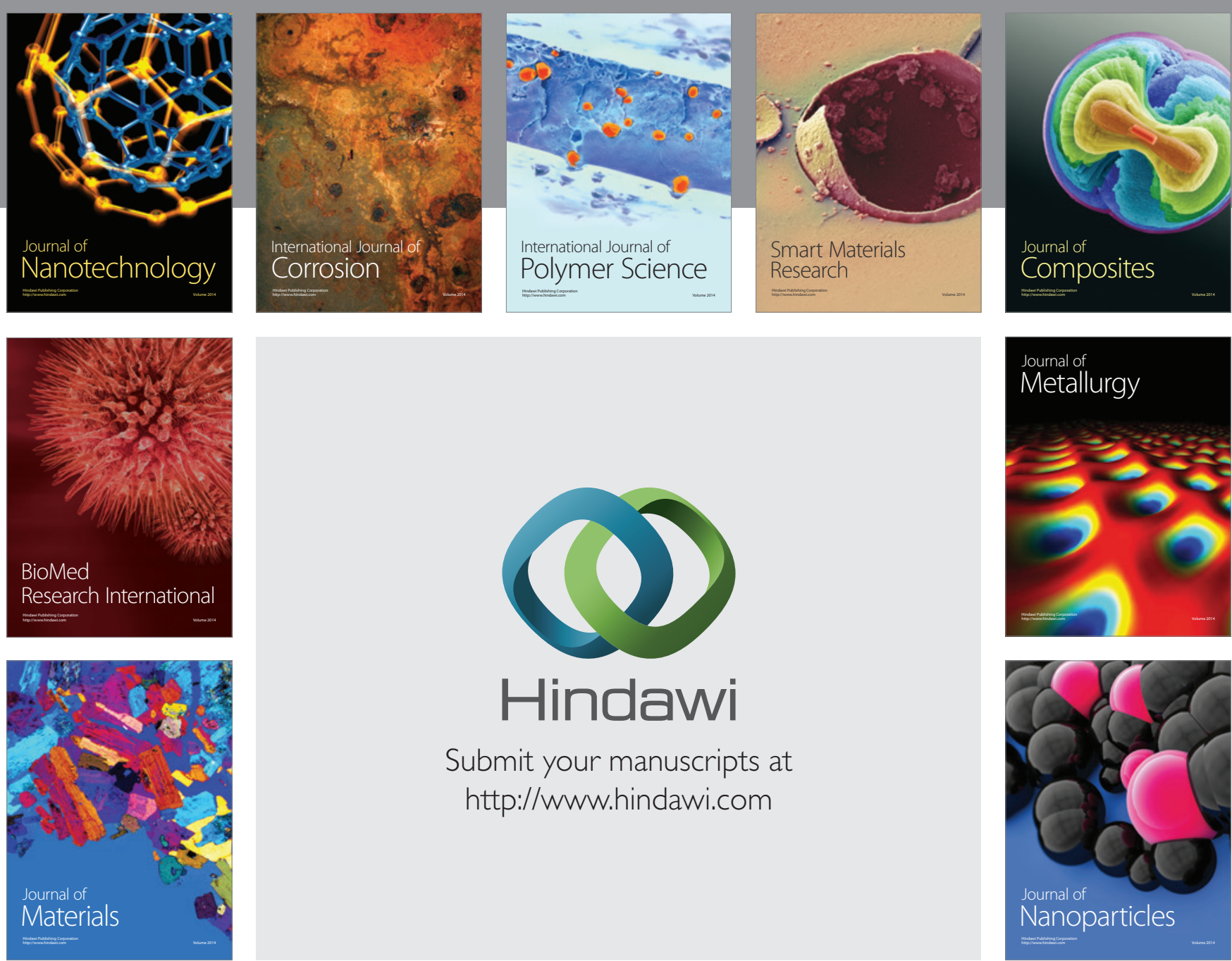

\section{Hindawi}

Submit your manuscripts at

http://www.hindawi.com

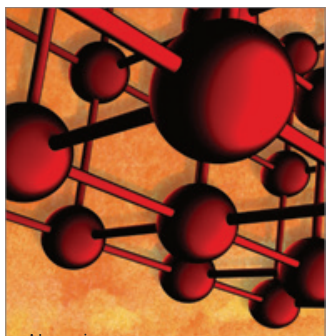

Materials Science and Engineering
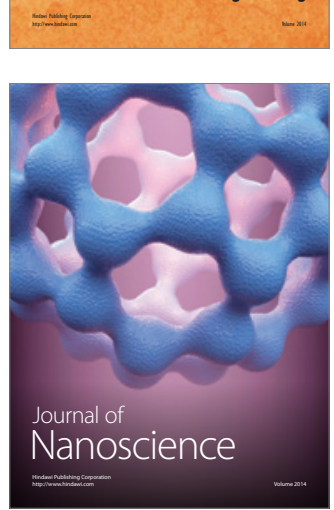
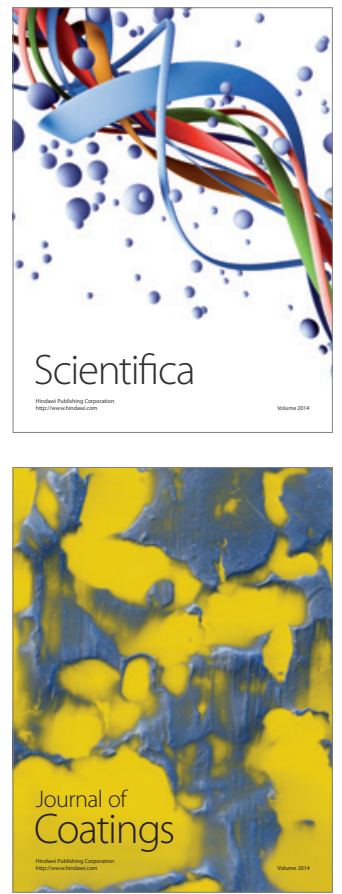
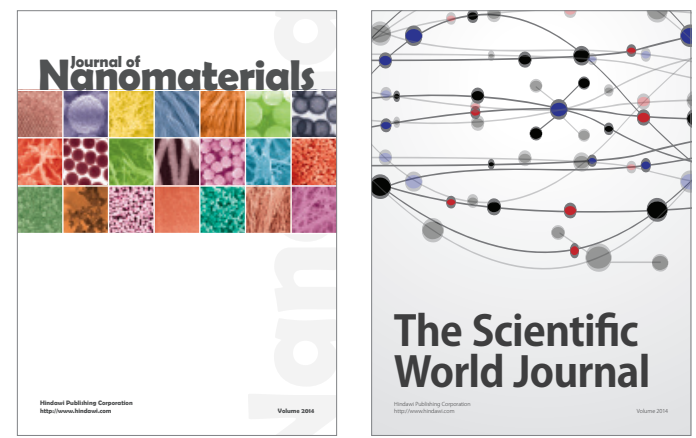

The Scientific World Journal
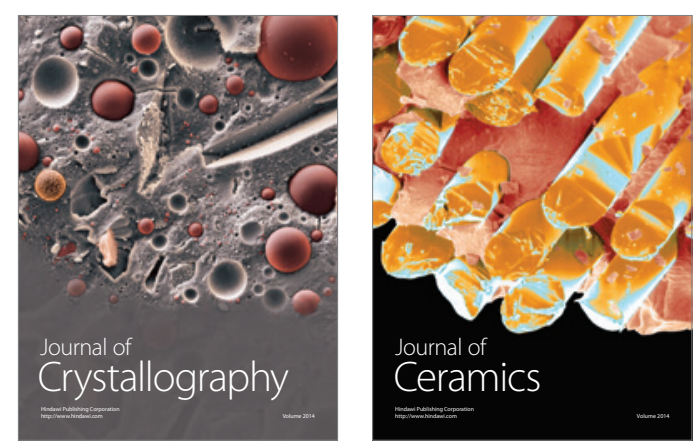
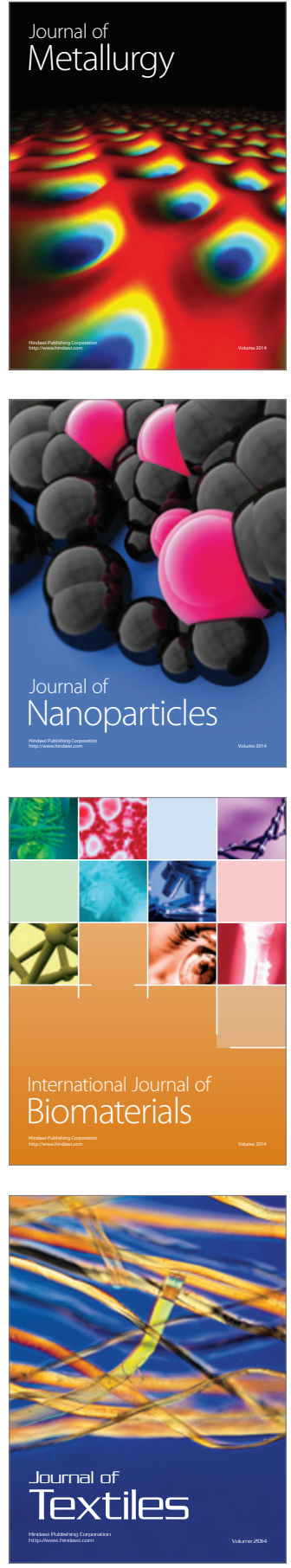